\title{
P02-60
}

\section{SUBJECTIVE HEALTH COMPLAINTS IN A SAMPLE WITH MORBID OBESITY AND THE COMPLAINTS' RELATION WITH WORK ABILITY}

\author{
H.Ø. Lier ${ }^{1}$, E. Biringer ${ }^{1}$, H. Eriksen ${ }^{2}$, T. Tangen ${ }^{3}$ \\ ${ }^{1}$ Section of Psychiatric Research, Division of Psychiatry, Helse Fonna HF, Haugesund, ${ }^{2}$ Unifob, ${ }^{3}$ Section of Psychiatry, Insitute of \\ Clinical Medicine, University of Bergen, Bergen, Norway
}

Background and aims: Obesity is associated with psychological, social and physical problems. The aim of this study was to examine the prevalence of subjective health complaints and their impact on work ability in a sample with morbid obesity.

Method: Fortysix patients, 31 women and 15 men, aged 23 to 65 years (mean 43.7, s.d. 10.7), with BMI from 37 to $60 \mathrm{~kg} / \mathrm{m}^{2}$ (mean $45 \mathrm{~kg} / \mathrm{m}^{2}$, s.d. 5.02), on a waiting list for bariatric surgery participated.Subjective health complaints were measured by the 29 -items Subjective Health Complaint Inventory. Five subscales were computed; Allergy, Flu, Musculoskeletal pain, Gastrointestinal problems and Pseudoneurology.

Results: All participants reported subjective health complaints the last month, in particular they suffered from musculoskeletal (mean 8.2, s.d. 5.46), pseudoneurological (mean 4.7, s.d. 4.31) and gastrointestinal (mean 3.2, s.d. 5.46) complaints. Mean sickness absence the last year was 185 days (s.d. 163.32). Days of sickness absence were significant correlated with the Musculoskeletal $(r=.35, p=.023)$ and Pseudoneurological $(r=.40, p=.009)$ subscales.

Conclusion: All patients reported subjective health complaints, with mean levels of symptoms considerably higher than in the general population. In particular, levels of musculoskeletal and pseudoneurological complaints were high, and these complaints were significantly related to work absence. It thus seems like subjective health complaints influence work ability to a significant degree in patients with morbid obesity. 